\title{
MANAGEMENT OF ENDOCRINE DISEASE Morbidity in polycystic ovary syndrome
}

\author{
Dorte Glintborg and Marianne Andersen
}

Department of Endocrinology, Odense University Hospital, Odense C, Denmark
Correspondence should be addressed to D Glintborg

Email

dorte.glintborg@rsyd.dk

\begin{abstract}
Polycystic ovary syndrome (PCOS) is the most prevalent endocrine condition in premenopausal women. The syndrome is characterized by hyperandrogenism, irregular menses and polycystic ovaries when other etiologies are excluded. Obesity, insulin resistance and low vitamin D levels are present in more than $50 \%$ patients with PCOS, these factors along with hyperandrogenism could have adverse effects on long-term health. Hyperinflammation and impaired epithelial function were reported to a larger extent in women with PCOS and could particularly be associated with hyperandrogenism, obesity and insulin resistance. Available data from register-based and data linkage studies support that metabolic-vascular and thyroid diseases, asthma, migraine, depression and cancer are diagnosed more frequently in PCOS, whereas fracture risk is decreased. Drug prescriptions are significantly more common in PCOS than controls within all diagnose categories including antibiotics. The causal relationship between PCOS and autoimmune disease represents an interesting new area of research. PCOS is a lifelong condition and long-term morbidity could be worsened by obesity, sedentary way of life, Western-style diet and smoking, whereas lifestyle intervention including weight loss may partly or fully resolve the symptoms of PCOS and could improve the long-term prognosis. In this review, the possible implications of increased morbidity for the clinical and biochemical evaluation of patients with PCOS at diagnosis and follow-up is further discussed along with possible modifying effects of medical treatment.
\end{abstract}

\section{Introduction}

The prevalence of polycystic ovary syndrome (PCOS) is more than $10 \%$ in reproductive-aged women when the Rotterdam criteria are applied (1). The Rotterdam criteria include irregular ovulation, biochemical/clinical hyperandrogenism, polycystic ovaries and the exclusion of other causes for the patient's signs and symptoms (2).
Approximately $75 \%$ patients with PCOS are overweight or obese and central obesity is present also in normal weight PCOS patients $(3,4)$. The pathogenesis of PCOS involves insulin resistance and hyperandrogenism. These two factors are associated with subclinical inflammation, the metabolic syndrome, increased risk of type 2 diabetes (T2D)

\section{Invited Author's profile}

Dorte Glintborg MD, PhD, DMSc has been a medical doctor since 1999 and specialist in medical endocrinology since 2011. She is currently a consultant at Odense University Hospital, Department of Endocrinology within the specialist areas of pituitary, gonadal and adrenal diseases. She has also been an Associate professor at the University of Southern Denmark since June 2016. Professor Glintborg has been a member of the Nordic PCOS awareness Group and the Danish Endocrine Society. She has 66 published articles mainly within the research areas of PCOS, hirsutism, pituitary diseases and hypogonadism.

() 2017 European Society of Endocrinology Printed in Great Britain
Published by Bioscientifica Ltd. 
and may be associated with increased risk of cardiovascular disease (5). Hyperinflammation in PCOS could also affect autoimmune function (6) and thereby increase the risk of thyroid and respiratory disease (7). Furthermore, the presence of insulin resistance, obesity and hyperinflammation in PCOS theoretically increase the risk of gallstones, cancer disease and overall mortality (7). Hirsutism is present in 20-25\% reproductive-aged women and more than $80 \%$ women with hirsutism are diagnosed with PCOS $(5,8)$. Hirsutism and obesity in patients with PCOS are associated with decreased quality of life, which could increase the risk depression (9).

The majority of previous studies focused on the presence of individual metabolic risk markers in PCOS, whereas limited data are available regarding morbidity evaluated by international classification of diseases (ICD10) codes and drug prescriptions in well-described study populations with $\operatorname{PCOS}(7,9,10)$. The aim of this review is to give an overview of morbidity in patients with PCOS. We included studies with hard end points regarding the presence and/or medical treatment of a wide range of diseases focusing on metabolic and psychiatric diagnoses in patient populations with PCOS. The possible impact of increased morbidity on the evaluation, treatment and follow-up in patients with PCOS is also discussed along with possible modifying effects of age, BMI, ethnicity, lifestyle and medical treatment of PCOS.

\section{Methods}

We searched for articles in PubMed using the terms: population-based PCOS, morbidity PCOS, medicine prescriptions PCOS, drug prescriptions PCOS, registerbased PCOS, mortality PCOS, data linkage PCOS and prognosis PCOS. Further relevant studies were identified by cross search from reference lists in identified studies. For each identified diagnosis we also performed a search including this diagnosis combined with PCOS (T2D PCOS, metabolic syndrome PCOS, etc.). We excluded studies on fertility treatment, pregnancy and pregnancy outcomes.

\section{Cardiometabolic disease in PCOS}

More than $50 \%$ of patients with PCOS are insulin resistant (11). Insulin resistance is closely associated with BMI, but is also present in normal weight patients with PCOS (12). Pancreatic beta-cell dysfunction is required for the development of T2D, dysglycemia develops when the pancreatic beta-cell is no longer able to secrete sufficient insulin to meet the increased requirements in insulin resistance (13). The elements of the metabolic syndrome in PCOS include waist circumference $\geq 88 \mathrm{~cm}$, impaired glucose tolerance, blood pressure $>130 / 85 \mathrm{mmHg}$, highdensity lipoprotein (HDL) $<1.3 \mathrm{mmol} / \mathrm{L}$ and triglyceride (TG) $>1.7 \mathrm{mmol} / \mathrm{L}(2)$. Nearly $50 \%$ of patients with PCOS fulfill the criteria of the metabolic syndrome $(12,14)$. It is currently estimated that approximately $75 \%$ of women with PCOS are overweight or obese, but no populationbased studies are available (4). In register-based studies, the prevalence of diagnosis of obesity was $13-16 \%$ in patients with PCOS compared with $1.4-3.7 \%$ in controls $(7,10)$. Central obesity established by waist circumference or dual-energy X-ray absorptiometry was an independent predictor of insulin resistance in PCOS $(15,16)$, supporting that a central fat distribution increased the metabolic risk.

The prevalence of diabetes in cross-sectional studies in PCOS was $1.5-10 \%(7,12,14,17)$ and in a recent metaanalysis, the odds ratio for T2D was 4.43 (95\% confidence interval 4.06-4.82) in patients with PCOS compared with controls (18). It is therefore recommended that all patients with PCOS should be screened for T2D by the time of diagnosis (2) and recent guidelines recommended that glucose metabolism was assessed by an oral glucose tolerance test (OGTT) (19). However, the diagnosis of T2D was closely associated with BMI and in previous studies few patients with a BMI $<25 \mathrm{~kg} / \mathrm{m}^{2}$ were diagnosed with T2D during OGTT: 0/298 (0\%) (20), 1/104 (0.9\%) (21), 1/102 (1.0\%) (12) and 1/57 (1.8\%) (11). Therefore, the value of performing OGTT in normal weight patients with PCOS may be limited. Some guidelines suggested that OGTT could be performed only in high-risk patients with BMI $>30 \mathrm{~kg} / \mathrm{m}^{2}$, age $>40$ years, previous gestational diabetes mellitus or a family history of T2D $(12,20,22)$. Up to $30 \%$ patients with diabetes would, however, not be diagnosed if these criteria for performing OGTT were applied (20). Pre-diabetes is defined as blood glucose levels higher than normal but below diabetes thresholds (23). Pre-diabetes is diagnosed in patients with impaired fasting glucose (fasting glucose $\geq 6.1 \mathrm{mmol} / \mathrm{L}$ and $<7.0 \mathrm{mmol} / \mathrm{L}$ ), impaired glucose tolerance $(2 \mathrm{~h}$ glucose levels $\geq 7.8 \mathrm{mmol} / \mathrm{L}$ and $<11.0 \mathrm{mmol} / \mathrm{L}$ during OGTT) and/or HbA1c 5.7-6.4\% (23). The prevalence of impaired glucose tolerance in PCOS was $10-36 \%(12,14,17)$ and the odds ratio for impaired glucose tolerance was 2.48 (95\% confidence interval 1.63-3.77) in patients with PCOS compared with controls (18). In the general population, around 5-10\% individuals with pre-diabetes convert to diabetes per year and up to 70\% individuals with pre-diabetes will 
develop diabetes (23). The risk for deteriorated glucose tolerance was high during follow-up in PCOS $(14,24)$. American patients with PCOS had an 8-year incidence of $13.4 \%$ for T2D (25) and 16.4\% Australian patients with PCOS developed T2D during 6 years of follow-up (24). In these studies, the most important predictive factor for the development of T2D was obesity $(14,24)$. We reevaluated 69 Danish hirsute patients with average BMI $25 \mathrm{~kg} / \mathrm{m}^{2}$ after a median observation period of 4 years (26). During follow-up, 8.5\% patients were diagnosed with T2D and deteriorated glucose levels were seen in both normal weight and obese individuals (26). HbA1c has higher repeatability than fasting glucose and can be assessed in the non-fasting state (27), but HbA1c had low sensitivity for the diagnosis of impaired glucose tolerance and T2D when OGTT was used as the gold standard (20, 22 , 28). In non-PCOS populations, HbA1c was more strongly associated with risk of cardiovascular disease and death from any cause than fasting glucose $(29,30,31)$. In conclusion, available data support that prospective screening for diabetes is needed in all patients with PCOS irrespective of $\mathrm{BMI}(5,32)$. The intervals for screening, however, need to be discussed and whether these intervals could be prolonged in young and lean patients with PCOS and no family history of T2D. Yearly screening with HbA1c in patients with PCOS and pre-diabetes and/or on metformin treatment could be a feasible method in daily clinical setting. Whether HbA1c is superior to OGTT regarding long-term metabolic and cardiovascular risk in PCOS must be established in prospective studies.

It was estimated that $70 \%$ newly diagnosed women with PCOS had borderline or high lipid levels (33), including increased total cholesterol, TG, LDL or decreased HDL levels $(34,35)$. In a Danish study population with median BMI $27 \mathrm{~kg} / \mathrm{m}^{2}, 41 \%$ patients with PCOS had HDL $<1.29 \mathrm{mmol} / \mathrm{L}$ and $21 \%$ patients had TG $>1.68 \mathrm{mmol} / \mathrm{L}$ (36). In register-based studies, the diagnosis of dyslipidemia was three times increased in patients with PCOS versus controls and the prescription of anti-lipids was two times higher in PCOS $(7,10)$. The percentage of patients with PCOS treated with anti-lipids was, however, only $1.5 \%$ (7). Most women with PCOS seek help in young age for irregular menses, hirsutism and infertility concerns (37). The absolute risk for cardiovascular events in young women is low and treatment with statins is rarely indicated in reproductive-aged women with PCOS. In recent studies, simvastatin decreased androgen levels (38), but was associated with increased insulin resistance (39). There are insufficient safety data on treatment with statins during pregnancy. It remains to be established whether prospective monitoring of lipid profiles is indicated in young women with PCOS who have no presence of increased cardiovascular risk (cardiovascular disease, diabetes, hypertension, familial dyslipidemia).

The diagnosis of hypertension was two times increased in PCOS and the prescription of antihypertensive drugs was two times higher in patients with PCOS versus controls $(7,10)$; however, only $1.8 \%$ (7) and 3.8\% (10) of patients with PCOS had a diagnosis of hypertension. Guidelines recommended prospective yearly measurements of blood pressure in women with PCOS (32), but limited data supported that these recommendations should be applied in all women with PCOS. In a Danish study population of women with PCOS, the prevalence of systolic blood pressure $>130 \mathrm{mmHg}$ was $46.3 \%$ and diastolic blood pressure $>85 \mathrm{mmHg}$ was $37.6 \%$ (36). A Dutch study reported increased risk of hypertension especially in young patients with PCOS, but patients with PCOS were more obese than controls (40). A retrospective study in a cohort of women with PCOS did not confirm a higher incidence of hypertension after correcting for BMI (41). The risk of hypertension especially in young women with PCOS should be evaluated in future studies and it remains to be established whether prospective blood pressure measurements are needed in young, lean women with PCOS and no presence of cardiovascular risk markers.

Patients with PCOS could have a more unfavorable lifestyle compared with healthy women. Women with PCOS had impaired suppression of ghrelin secretion following meals (42) and increased risk of reactive hypoglycemia (43), which could increase appetite and weight gain. Increased fat ingestion in PCOS patients versus controls was reported in some studies $(44,45)$. The prevalence of eating disorders was nearly $40 \%$ in women presenting with hirsutism (46) and conversely, PCOS was overrepresented in bulimic women (47).

We reported previously a higher prevalence of smoking in PCOS versus controls (48) and smoking was associated with increased adrenal responsiveness, a more adverse lipid profile (48) and insulin resistance (49) in PCOS.

The long-term metabolic-vascular risk of PCOS is debated $(5,50)$. Coronary artery calcification and echocardiographic abnormalities were more common in PCOS $(51,52,53)$, but limited data were available from prospective studies on well-defined PCOS populations (54). A recent meta-analysis included five studies assessing risk of nonfatal and fatal coronary heart disease and stroke in women with PCOS. The pooled relative risk was 2.02 (95\% confidence interval 1.47-2.76) for coronary heart 
disease or stroke in women with PCOS compared with controls and 1.55 (95\% confidence interval 1.27-1.89) after adjusting for BMI (55). In two recent register-based studies, the diagnosis of PCOS was associated with a two times increased risk of stroke and thrombosis $(7,10)$. The risk of having cardiovascular disease by the time of PCOS diagnosis was not increased (7), but the risk increased 2.9 times during follow-up (10). The presence of individual Rotterdam criteria was not associated with cardiometabolic outcomes (7). Four different PCOS phenotypes may be defined when the Rotterdam criteria are applied (56). Patients fulfilling the National Institutes of Health criteria for PCOS could have a more adverse metabolic risk than patients with milder phenotypes (57) and the metabolic disturbances of PCOS were more pronounced in hyperandrogen patients compared with patients with no hyperandrogenemia (58). The PCOS phenotype may therefore be a predictor of metabolic and cardiovascular risk, but long-term studies are needed to confirm this hypothesis. Furthermore, the clinical and biochemical manifestations of PCOS may be modified according to lifestyle intervention and changes in weight (13). Weight gain may induce the PCOS phenotype in predisposed women and medical intervention or a change in lifestyle resulting in weight loss may fully resolve PCOS and restore fertility $(13,59)$. It remains to be established how patients may shift between different phenotypes and how this should affect evaluation and follow-up.

Increasing age was associated with higher $2 \mathrm{~h}$ and area under the curve for glucose during OGTT (37), supporting loss of beta-cell function and increased risk for T2D and cardiovascular risk factors increased with age in PCOS (37). The available data support that the metabolicvascular risk is increased in PCOS, but more data are needed especially in postmenopausal study populations. Furthermore, ethnicity must be considered as a modifying risk factor in PCOS (60). Lim et al. reported a similar association between PCOS and overweight or obesity in Caucasian and Asian women (4). The relative risk for obesity was higher in Caucasian women compared with Asian women, whereas central obesity was comparable in the two groups (4). North European women with PCOS were significantly older and more obese, had higher blood pressure, a more adverse lipid profile and smoked at a higher frequency by the time of referral compared with women originating from the Middle East, for whom insulin sensitivity was higher (36). Immigrants in Western countries may be at increased risk for lifestyle diseases such as obesity and diabetes (60). Increased risk for diseases may be attributable to genetic predisposition or to environmental influences such as different exercise or eating habits. In addition, some ethnic subgroups may be relatively protected against the long-term side effects of PCOS (36). It is generally recommended that patients with PCOS are screened for cardiovascular risk factors by the time of diagnosis (2), whereas the intervals for subsequent follow-up are debated. More studies are needed to determine whether different age groups and ethnic groups with PCOS should be monitored differently.

Treatment modalities in PCOS aim at decreasing hyperandrogenism, inducing weight loss and improving insulin sensitivity. The long-term effect of medical treatment on metabolic-vascular outcomes needs to be considered especially as some medical interventions could deteriorate the metabolic risk profile in PCOS. Treatment with oral contraceptives regulates menstrual cycles and sex hormone-binding globulin levels are increased, leading to decreased levels of free testosterone and decreased hirsutism scores (61). The possible metabolic side effects of oral contraceptives are debated. In meta-analyses, treatment with oral contraceptives was associated with unchanged fasting insulin in PCOS (62), but fasting insulin is only a rough measure of insulin resistance (13) and different generation oral contraceptives could have divergent effects on metabolic risk (63). One year's treatment with a third-generation oral contraceptive was associated with a median weight gain of $1.2 \mathrm{~kg}$, which was evenly distributed on the upper and lower body regions and was unassociated with changes in testosterone levels (64). Currently, treatment with a second-generation oral contraceptives is often a first choice in patients with PCOS due to low thromboembolic risk $(65,66)$, but the antiandrogen effect of newer generations of oral contraceptives could have less adverse effects on insulin resistance (67). The incidence of venous thromboembolism was 1.5 -fold increased among women with PCOS not taking oral contraceptives compared with controls and twofold increased among women with PCOS who were taking combined oral contraceptives compared with controls (68). Furthermore, the higher generation of oral contraceptives may further increase the coagulability as fourth-generation oral contraceptives containing drospirenone had the highest thromboembolic risk (69). In our register-based study, five of six patients with thrombosis had been on oral contraceptives (7).

Even a minor weight loss of 5-10\% improves insulin sensitivity, ovulation rate and cardiovascular risk factors in overweight women with PCOS (70). The metabolic rate measured by indirect calorimetry was not decreased in PCOS (71) and during lifestyle intervention, the ability 
to lose weight was comparable in women with PCOS and weight-matched controls $(72,73)$, but adherence to lifestyle intervention was limited (70).

Treatment with metformin increases insulin sensitivity and improves ovulatory function in PCOS (61), whereas androgen levels and hirsutism scores are only mildly improved or unchanged $(61,74)$. The first-line treatment modalities for pre-diabetes are lifestyle intervention and metformin treatment (75). Diet modification was the most effective treatment modality to cause significant weight loss, whereas the additional effect of metformin was only marginal (70). Treatment with metformin for 6 months or less had a limited effect on weight loss (74), whereas 12 months treatment induced a median weight loss of $3 \mathrm{~kg}$ (64). Decreased adipokine and ghrelin levels during metformin treatment could induce weight loss $(74,76)$, but this hypothesis needs further testing.

\section{Bone mineral density and fractures}

Hyperandrogenemia, increased androgen sensitivity, adiposity and hyperinsulinemia in PCOS could be associated with higher bone mineral density and protect against the development of osteoporosis $(77,78,79$, 80,81 ), whereas amenorrhea, increased risk of T2D, low growth hormone levels and increased cortisol may be associated with lower bone mineral density (82). Furthermore, vitamin D levels were lower in patients with PCOS and hirsutism versus controls $(83,84)$ and $31-85 \%$ patients with PCOS had vitamin D levels $<50 \mathrm{nmol} / \mathrm{L}$ (85), which could be associated with defects in bone mineralization, increased bone turnover and increased fracture risk (81).

Bone mineral density was normal or higher in patients with PCOS and hirsute patients compared with controls (81). In a recent register-based study, the prevalence of prior fractures was significantly lower in patients newly diagnosed with PCOS versus controls (7). The mean age of included women was 30 years and the prevalence of osteoporosis could therefore not be evaluated (7). One Swedish study found no difference in fracture risk over more than 20 years in 25 postmenopausal women diagnosed previously with PCOS compared with 68 controls (86). In a recent register-based study including 19199 women with PCOS, we found that the risk of fractures was reduced by about a third in patients with PCOS (82). The risk reduction tended to be more pronounced in women diagnosed with PCOS at a younger age, whereas the presence of hyperandrogenemia did not modify the fracture risk (82). The fracture risk reduction was more pronounced in fractures of the hands, head and face than at major osteoporotic sites and the risk reduction could not be explained by a reduced exposure to daily trauma in PCOS (82).

Decreased fracture risk in PCOS could be modified by medical treatment. Normalized menstrual cycles during oral contraceptive treatment could improve bone mineral density, but this effect could be counteracted by decreased androgen levels. Oral contraceptives did not affect bone mineral density levels in healthy females (87, 88) and during 12 months treatment in hirsute patients $(89,90)$. The use of oral contraceptives with low estrogen content shortly after menarche could, however, have a negative impact on peak bone mass and should be used with caution in this age group (88). Oral contraceptive use in perimenopausal women was associated with improved bone mineral density (88), but due to increased risk of thrombosis, oral contraceptives are generally not recommended in this age group.

Treatment with insulin sensitizers could lead to decreased insulin and testosterone levels, which could have adverse effects on bone mineral density, but could be counterbalanced by normalized estrogen and progesterone levels. Metformin stimulated osteoblast proliferation in vitro and increased levels of type-I collagen and alkaline phosphatase in osteoblast-like cells (91). In adolescents, bone mineral density and bone geometry $Z$-scores were unchanged following 1.9 years of combined metformin/ oral contraceptive/antiandrogen or metformin treatment (92). Studies in diabetic populations suggested a minor protective effect of metformin on bone mineral density levels (91), but high glucose levels had adverse effects in bone metabolism and bone strength, leading to impaired bone quality and increased fracture risk (91). It, therefore, remains to be determined whether the effects of metformin on bone mineral density can be extrapolated to populations with normal glucose levels including patients with PCOS.

Peroxisome proliferator-activated receptor gamma (PPAR $\gamma$ ) agonist treatment is associated with decreased peripheral adipocyte lipolysis, decreased free fatty acid levels and fat redistribution toward peripheral fat (93). In PCOS, PPAR $\gamma$ agonist treatment increased insulin sensitivity, improved ovulatory function and decreased inflammatory markers without significant effects on testosterone levels (94). Thiazolidinediones may, however, affect regulation of the pluripotent mesenchymal stem cells and stimulate differentiation into adipocytes in preference of osteoblasts (95). Bone mineral density and markers of osteoblast activity significantly decreased in 
PCOS patients treated with pioglitazone (96) and PPAR $\gamma$ agonist treatment had similar adverse effects on bone mineral density in patients with PCOS, patients with T2D (97) and in healthy postmenopausal women (98).

\section{Autoimmune, inflammatory and infectious diseases in PCOS}

Increased inflammatory status, unbalanced estrogen/ progesterone secretion or still unknown mechanisms may impair the immune function in PCOS (99). In a recent register-based study, the overall presence of thyroid diseases was 3.6 times increased in PCOS versus controls and prescriptions of thyroid medicine were three times increased in patients (7). These data were in agreement with clinical studies reporting that presence of thyroid autoantibodies and autoimmune thyroiditis was more prevalent in patients with PCOS compared with controls $(99,100)$. Similar mechanisms were suggested to affect respiratory health and to increase the risk of asthma in women with irregular menses (101). In two register-based studies, the relative risks of asthma were 1.5 (7) and 2.5 (10) in PCOS; these results underline the need for studies on pulmonary disease susceptibility in PCOS (7). Furthermore, the levels of various autoantibodies were higher in PCOS versus controls (6) and the risk of rheumatologic or other autoimmune diseases may also be increased in PCOS (6). Increased levels of islet autoantibodies causes destruction of the pancreatic beta cells and lead to type 1 diabetes. The prevalence of a diagnosis of type 1 diabetes was $0.9 \%$ in patients diagnosed with PCOS and the risk of type 1 diabetes was 1.8 times increased compared with controls (7). We are not aware of studies examining the prevalence of beta-cell autoantibodies in patients with PCOS. It was speculated that treatment with supraphysiological levels of insulin in type 1 diabetes could increase the risk of evolving PCOS (102). The prevalence of PCOS in women with type 1 diabetes was $40 \%$, biochemical hyperandrogenism was present in $20 \%$ of the patients and PCO was present in $50 \%$ (102). In patients with type 1 diabetes, the presence of PCOS was, however, not associated with differences in medical treatment and glycemic control (103) and the phenotype of women with PCOS was not affected by the presence of type 1 diabetes (103). The role of metformin treatment in patients with simultaneous type 1 diabetes and PCOS remains to be established.

Activation of the inflammatory system could have adverse effects on the risk of infectious diseases. The use of antibiotic treatment was 1.4 times higher one year before the diagnosis of PCOS compared with controls (7).
More studies are needed regarding the pattern of infectious diseases in patients with PCOS compared with controls.

\section{Gastrointestinal diseases in PCOS}

Gallstones are the most frequent and expensive of digestive diseases that require hospitalization (104). Gallbladder disease is associated with many of the characteristics of PCOS, for example, the metabolic syndrome, insulin resistance and particularly T2D (104). Hence, the findings of a three times increased risk of gallbladder disease in patients with PCOS and that $3.3 \%$ patients with PCOS had a previous diagnosis of cholecystitis were not surprising (7). The frequency of cholecystitis may be even higher in older or more obese study populations (104). Medical therapy may modify the risk of gallbladder disease, as metformin therapy increased gallbladder motility (105), whereas there are no data on oral contraceptive treatment and gallbladder disease in PCOS. Data from non-PCOS populations were reassuring as oral contraceptives had no impact on the occurrence of gallbladder disease (106).

In a recent meta-analysis, nonalcoholic fatty liver disease (NAFLD) was diagnosed three times more often in PCOS (107), these findings opted the authors to suggest that patients with PCOS should be screened with liver function test and for the metabolic syndrome (107). NAFLD may progress from simple steatosis to alcoholic steatohepatitis, liver fibrosis, cirrhosis and eventually hepatocellular carcinoma (107). We are not aware of studies on the risk of more severe stages of liver disease in PCOS. First-line treatment of NAFLD is lifestyle intervention and weight loss, but treatment with metformin was also associated with improved liver function (107). Oral contraceptive therapy may theoretically improve NAFLD in PCOS, as estrogen inhibited activation of stellate cells and decreased fibrogenesis in experimental models (108). Accordingly, the age of menopause was negatively associated with the risk of nonalcoholic fatty liver disease (108). To our knowledge no study has tested the effect of oral contraceptives on NAFLD in PCOS.

\section{Depression and psychiatric illness}

Quality of life is impaired in patients with PCOS (109, 110). SF-36 scores were comparable between patients with PCOS and patients with chronic diseases such as diabetes and asthma $(110,111)$. Especially, obesity and hirsutism were associated with impaired quality of life in PCOS $(110,112)$, whereas menstrual irregularities were less important (111). Depression was 2.8 times 
more common in Danish patients with PCOS versus controls and 1.9 times more patients than controls had prescriptions of antidepressants (7). We found a discrepancy between only $1.4 \%$ patients diagnosed with depression and as many as $16.3 \%$ patients treated with antidepressants (7), but the majority of patients may be treated for depression by their own general practitioner and only hospital diagnoses were included in the National Patient Register (7). During follow-up, 20\% reproductive-aged patients with PCOS living in our local area obtained prescriptions of antidepressants compared with $15 \%$ healthy controls (9). In contrast, some studies reported an up to eight fold increased risk of depression in PCOS $(109,110)$. Patients with PCOS could be medically undertreated or could have milder depression symptoms without need for medical treatment (113). A recent Cochrane review found lack of data on the use of antidepressants in patients with PCOS and studies on their effectiveness in PCOS were requested (114).

The use of anxiety medicine was higher in patients with PCOS compared with controls (7) and in a Taiwanese register-based study, the hazard ratio was 1.4 for anxiety disorders in PCOS (115). Anxiety could be associated with depression and low quality of life in PCOS, but more studies are needed to test this hypothesis.

Medical treatment of PCOS may modulate depressive symptoms. Oral contraceptives did not change depressive symptoms in 36 patients with PCOS despite more regular menses and decreased hirsutism (116), but no long-term randomized studies evaluated the effects of oral contraceptives on quality of life. In previous studies, decreased quality of life in PCOS was associated to increased body weight (110). In a prospective study, six months treatment with metformin significantly improved quality of life in 64 patients with PCOS (117). Improved quality of life was associated with weight loss and more regular menses (117). Physical activity and lifestyle intervention may improve quality of life, but more studies are needed to determine which treatment modalities should be advised in patients with PCOS and decreased quality of life.

The diagnoses of migraine/headache were two times higher in PCOS versus controls and correspondingly, patients with PCOS had a 1.7 times higher prescription rate of analgesics and migraine medicine (7). However, the mechanism for increased risk of migraine and headache in PCOS is undetermined and the association with testosterone is not straightforward as testosterone treatment improved symptoms of migraine in preand postmenopausal women (118), whereas decreased dihydrotestosterone levels during treatment with finasteride improved migraine symptoms (119). Furthermore, increased use of analgesic medicine in PCOS could be associated to use of oral contraceptives, decreased quality of life or the presence of somatic disease (7). Paracetamol and low-dose nonsteroid anti-inflammatory drugs (NSAID) can be bought by prescription or over the counter in Denmark and therefore the total use of these drugs in PCOS could not be established (7).

\section{Cancer disease}

Risk factors for endometrial cancer are obesity, nulliparity, age $>50$ years, early menarche or late menopause, infertility, hypertension, diabetes, chronic anovulation, unopposed estrogen supplementation and tamoxifen use (120). Several of these findings are common in PCOS, it was therefore speculated that PCOS patients carry an increased risk of endometrial cancer, but data from epidemiological studies were conflicting (121). In some study populations the risk of endometrial cancer in PCOS was three to four times increased, whereas this could not be confirmed in other studies $(120,122$, 123). The highest risk for endometrial cancer was found in women with PCOS $<50$ years (122). As discussed previously, the diagnosis of PCOS could impact the risk of endometrial cancer (120). Women with a diagnosis of PCOS may be more aware of bleeding disturbances and oral contraceptives are often prescribed, which could both prevent premalignant or cancerous gynecologic conditions (120). Therefore, women with undiagnosed PCOS might have an even higher risk of endometrial cancer than reported in previous studies.

Nulliparity, obesity and unopposed estrogen supplementation could increase the risk of breast cancer and ovarian cancer, whereas treatment with oral contraceptives decreases the risk of ovarian cancer (122). The risk of ovarian and breast cancer was not increased in patients with PCOS $(122,123,124)$, whereas the risk of ovarian cancer was increased in patients aged $<50$ years (123).

The overall diagnosis of malignant disease was two times increased in a Danish population newly diagnosed with PCOS (7). During follow-up, the risk of kidney, colon and brain cancer was significantly increased in patients with PCOS (122). The number of cases was relatively low and the results need to be reproduced in patients with PCOS from other countries. Obesity and smoking increase the risk of kidney and colon cancer and it remains to be established whether 

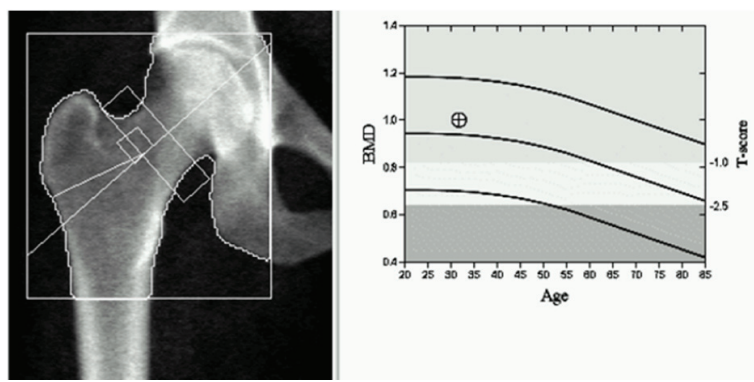

\section{Autoimmune disease}

Decreased fracture risk
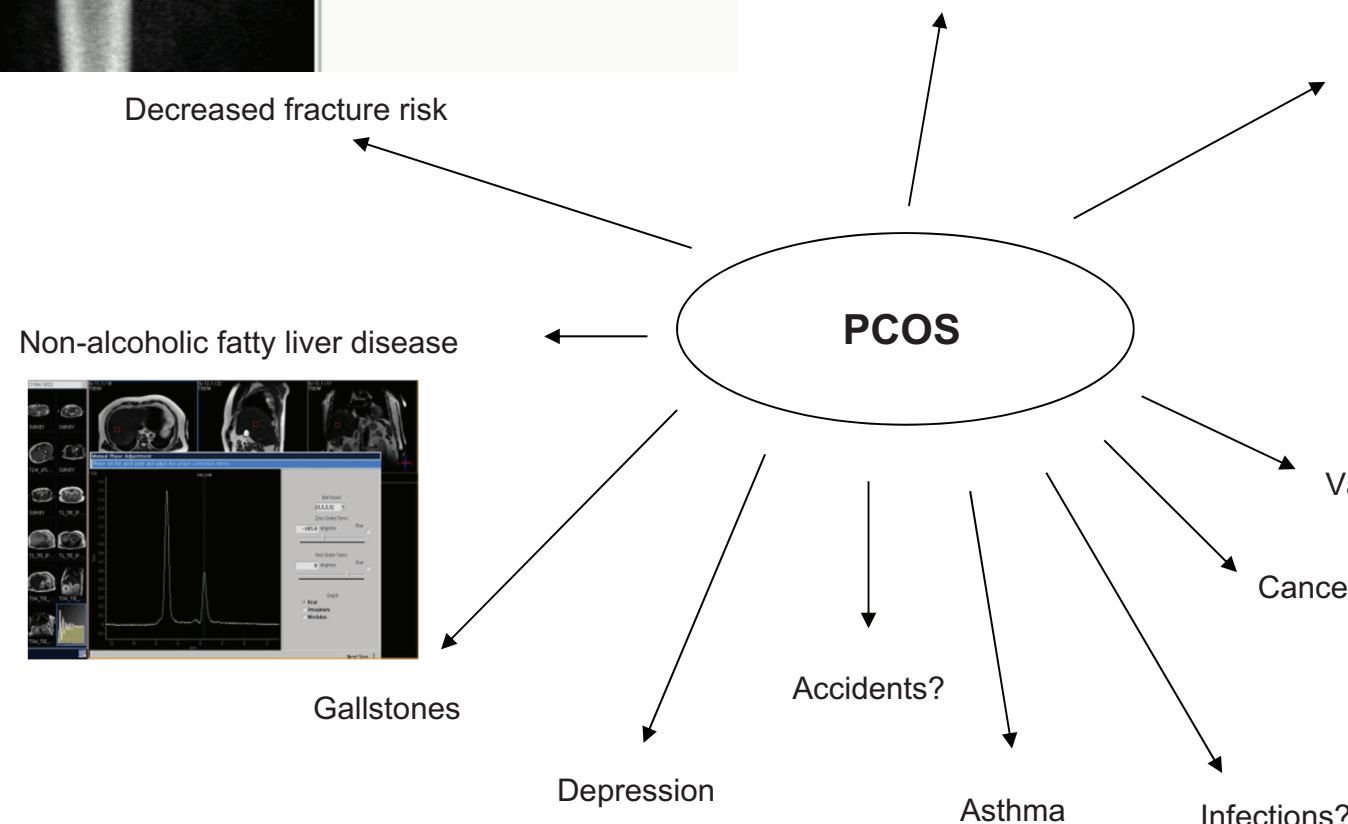

Non-alcoholic fatty liver disease

Depression

Gallstones
Pcos

Accidents?

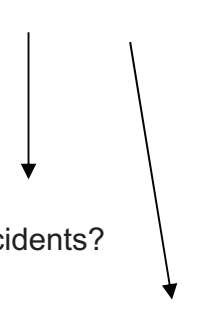

Asthma

Metabolic disease

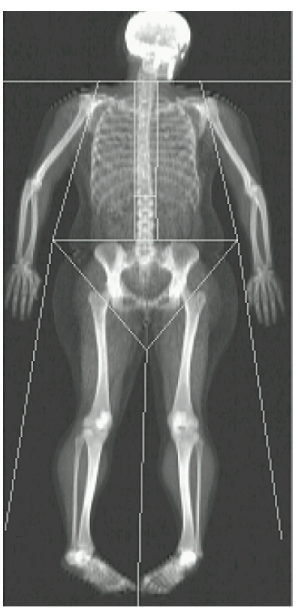

\section{Figure 1}

Morbidity in PCOS. A full colour version of this figure is available at http://dx.doi.org/10.1530/EJE-16-0373.

the association between PCOS and these cancer types is attenuated after adjustment for BMI and smoking status (122). Furthermore, obesity, smoking and ingestion of more fat in patients with PCOS could increase the risk of several other cancer types. Insulin is an important growth factor and the insulin receptor was overexpressed in cancer cells (125). Insulin resistance and the following hyperinsulinemia in PCOS could therefore be an independent risk factor of malignant disease (125).

The majority of brain tumors originated from the pituitary gland (122) and the increased risk of brain tumors remained significant after omitting cases diagnosed within the first year after PCOS diagnosis (122). The mechanism for a possible increased risk of pituitary tumors in PCOS remains to be established.

\section{Overall mortality and morbidity in PCOS}

The Charlson Comorbidity Index is based on 19 comorbid conditions (myocardial infarction, congestive heart failure, peripheral vascular disease, cerebrovascular disease, dementia, chronic pulmonary disease, connective tissue disease, ulcer disease, diabetes, hemiplegia,

Table 1 Effects of medical treatment on morbidity in PCOS.

\begin{tabular}{|c|c|}
\hline & Metabolic syndrome \\
\hline Lifestyle & $\downarrow$ \\
\hline OCP & $(\uparrow)$ \\
\hline Metformin & $\downarrow$ \\
\hline
\end{tabular}
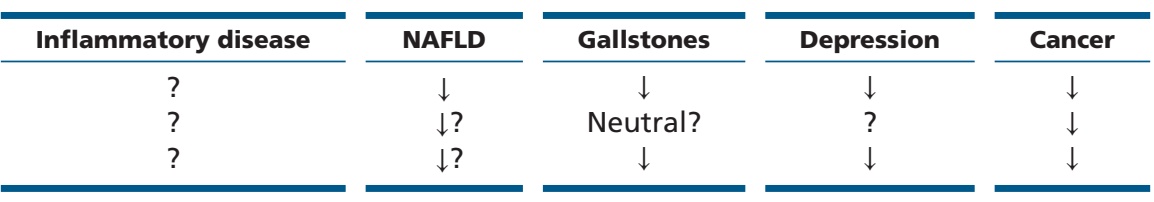

NAFLD, non-alcoholic fatty liver disease; OCP, oral contraceptives

$\downarrow$ decreased risk, $\uparrow$ increased risk, ? undetermined. 
moderate or severe renal disease, diabetes with end organ damage, any tumor, leukemia, lymphoma, mild liver disease, moderate or severe liver disease, metastatic solid tumor and AIDS) (126) and can be calculated from the ICD-10 operationalization by Quan et al. (127). By the time of diagnosis, the Charlson Index was 1.6 times higher in patients with PCOS than controls, which supported an overall increased morbidity in PCOS (7). During a median follow-up of 4.7 years (interquartile range 2.0-8.6 years), the mortality risk was not significantly increased in 21740 women with PCOS (128). The mean age of included patients was, however, only 27.1 years and lack of power or limited follow-up period in young individuals could explain that the mortality rate was not increased in PCOS $(128,129)$.

Recently, it was reported that patients with PCOS were more often involved in accidents (10) and the prevalence of hospital contacts regarding sprains and strains was increased in PCOS (82). It remains to be established whether a different behavioral risk profile between patients with PCOS and controls could explain these findings. Data regarding physical activity in PCOS were conflicting and showed similar (130) or decreased (131) physical activity in women with PCOS compared with controls.

\section{Conclusion}

Morbidity in PCOS regarding nearly all organ systems is significantly increased (Fig. 1). Available data support that also young women with PCOS carry a high risk for disease, whereas fracture risk is decreased. Available guidelines especially covered metabolic-vascular outcomes, whereas the optimal screening program for other diseases remains to be determined. More data are needed regarding the possible modifying effects of PCOS phenotype on longterm outcome. Treatment with lifestyle intervention and metformin could be important tools for the prevention of adverse disease outcomes, whereas oral contraceptives could both be of benefit or harm (Table 1). When prescribing medical therapy the patient's individual risk has to be considered including age, BMI and ethnicity.

\section{Declaration of interest}

The authors declare that there is no conflict of interest that could be perceived as prejudicing the impartiality of the research reported.

\section{Funding}

This research did not receive any specific grant from any funding agency in the public, commercial or not-for-profit sector.

\section{References}

1 Conway G, Dewailly D, Diamanti-Kandarakis E, EscobarMorreale HF, Franks S, Gambineri A, Kelestimur F, Macut D, Micic D, Pasquali R et al. The polycystic ovary syndrome: a position statement from the European Society of Endocrinology. European Journal of Endocrinology 20144 1-29. (doi:10.1530/EJE-14-0253)

2 Rotterdam ESHRE/ASRM-Sponsored PCOS Consensus Workshop Group. Revised 2003 consensus on diagnostic criteria and longterm health risks related to polycystic ovary syndrome. Fertility and Sterility 20041 19-25. (doi:10.1016/j.fertnstert.2003.10.004)

3 Kirchengast S \& Huber J. Body composition characteristics and body fat distribution in lean women with polycystic ovary syndrome. Human Reproduction 20016 1255-1260. (doi:10.1093/ humrep/16.6.1255)

4 Lim SS, Davies MJ, Norman RJ \& Moran LJ. Overweight, obesity and central obesity in women with polycystic ovary syndrome: a systematic review and meta-analysis. Human Reproduction Update 20126 618-637. (doi:10.1093/humupd/dms030)

5 Glintborg D \& Andersen M. An update on the pathogenesis, inflammation, and metabolism in hirsutism and polycystic ovary syndrome. Gynecological Endocrinology 20104 281-296. (doi:10.3109/09513590903247873)

6 Hefler-Frischmuth K, Walch K, Huebl W, Baumuehlner K, Tempfer C $\&$ Hefler L. Serologic markers of autoimmunity in women with polycystic ovary syndrome. Fertility and Sterility 20107 2291-2294. (doi:10.1016/j.fertnstert.2009.01.056)

7 Glintborg D, Hass RK, Nybo M, Abrahamsen B \& Andersen M. Morbidity and medicine prescriptions in a nationwide Danish population of patients diagnosed with polycystic ovary syndrome. European Journal of Endocrinology 20155 627-638. (doi:10.1530/EJE14-1108)

8 Azziz R. The evaluation and management of hirsutism. Obstetrics and Gynecology 20035 995-1007. (doi:10.1097/00006250-20030500000029)

9 Altinok ML, Glintborg D, Depont CR, Hallas J \& Andersen M. Prescription of antidepressants is increased in Danish patients with polycystic ovary syndrome and is associated with hyperandrogenism. A population-based cohort study. Clinical Endocrinology 201380 884-889. (doi:10.1111/cen.12365)

10 Hart R \& Doherty DA. The potential implications of a PCOS diagnosis on a woman's long-term health using data linkage. Journal of Clinical Endocrinology and Metabolism 20153 911-919. (doi:10.1210/jc.2014-3886)

11 Legro RS, Kunselman AR, Dodson WC \& Dunaif A. Prevalence and predictors of risk for type 2 diabetes mellitus and impaired glucose tolerance in polycystic ovary syndrome: a prospective, controlled study in 254 affected women. Journal of Clinical Endocrinology and Metabolism 19991 165-169. (doi:10.1210/jcem.84.1.5393)

12 Glintborg D, Henriksen JE, Andersen M, Hagen C, Hangaard J, Rasmussen PE, Schousboe K \& Hermann AP. Prevalence of endocrine diseases and abnormal glucose tolerance tests in 340 Caucasian premenopausal women with hirsutism as the referral diagnosis. Fertility and Sterility 20046 1570-1579. (doi:10.1016/ j.fertnstert.2004.06.040)

13 Diamanti-Kandarakis E \& Dunaif A. Insulin resistance and the polycystic ovary syndrome revisited: an update on mechanisms and implications. Endocrine Reviews 20126 981-1030. (doi:10.1210/ er.2011-1034)

14 Ehrmann DA, Barnes RB, Rosenfield RL, Cavaghan MK \& Imperial J. Prevalence of impaired glucose tolerance and diabetes in women with polycystic ovary syndrome. Diabetes Care 19991 141-146. (doi:10.2337/diacare.22.1.141)

15 Manneras-Holm L, Leonhardt H, Kullberg J, Jennische E, Oden A, Holm G, Hellstrom M, Lonn L, Olivecrona G, Stener-Victorin E et al. Adipose tissue has aberrant morphology and function in 
PCOS: enlarged adipocytes and low serum adiponectin, but not circulating sex steroids, are strongly associated with insulin resistance. Journal of Clinical Endocrinology and Metabolism 20112 E304-E311. (doi:10.1210/jc.2010-1290)

16 Tosi F, Di SD, Kaufman JM, Bonin C, Moretta R, Bonora E, Zanolin E $\&$ Moghetti P. Total body fat and central fat mass independently predict insulin resistance but not hyperandrogenemia in women with polycystic ovary syndrome. Journal of Clinical Endocrinology and Metabolism 20152 661-669. (doi:10.1210/jc.2014-2786)

17 Palmert MR, Gordon CM, Kartashov AI, Legro RS, Emans SJ \& Dunaif A. Screening for abnormal glucose tolerance in adolescents with polycystic ovary syndrome. Journal of Clinical Endocrinology and Metabolism 20023 1017-1023. (doi:10.1210/jcem.87.3.8305)

18 Moran LJ, Misso ML, Wild RA \& Norman RJ. Impaired glucose tolerance, type 2 diabetes and metabolic syndrome in polycystic ovary syndrome: a systematic review and meta-analysis. Human Reproduction Update 20104 347-363. (doi:10.1093/ humupd/dmq001)

19 Salley KE, Wickham EP, Cheang KI, Essah PA, Karjane NW \& Nestler JE. Position statement: glucose intolerance in polycystic ovary syndrome a position statement of the androgen excess society. Journal of Clinical Endocrinology and Metabolism 200712 4546-4556. (doi:10.1210/jc.2007-1549)

20 Lerchbaum E, Schwetz V, Giuliani A \& Obermayer-Pietsch B. Assessment of glucose metabolism in polycystic ovary syndrome: $\mathrm{HbA1c}$ or fasting glucose compared with the oral glucose tolerance test as a screening method. Human Reproduction $201392537-2544$. (doi:10.1093/humrep/det255)

21 Vrbikova J, Fanta M, Cibula D, Vondra K \& Bendlova B. Impaired glucose metabolism in women with polycystic ovary syndrome. Gynecologic and Obstetric Investigation 20093 186-190. (doi:10.1159/000232574)

22 Celik C, Abali R, Bastu E, Tasdemir N, Tasdemir UG \& Gul A. Assessment of impaired glucose tolerance prevalence with hemoglobin $\mathrm{A}(1) \mathrm{c}$ and oral glucose tolerance test in 252 Turkish women with polycystic ovary syndrome: a prospective, controlled study. Human Reproduction 20134 1062-1068. (doi:10.1093/ humrep/det002)

23 Tabak AG, Herder C, Rathmann W, Brunner EJ \& Kivimaki M. Prediabetes: a high-risk state for diabetes development. Lancet 2012 9833 2279-2290. (doi:10.1016/S0140-6736(12)60283-9)

24 Norman RJ, Masters L, Milner CR, Wang JX \& Davies MJ. Relative risk of conversion from normoglycaemia to impaired glucose tolerance or non-insulin dependent diabetes mellitus in polycystic ovarian syndrome. Human Reproduction 20019 1995-1998. (doi:10.1093/humrep/16.9.1995)

25 Boudreaux MY, Talbott EO, Kip KE, Brooks MM \& Witchel SF. Risk of T2DM and impaired fasting glucose among PCOS subjects: results of an 8-year follow-up. Current Diabetes Reports 20061 77-83. (doi:10.1007/s11892-006-0056-1)

26 Andries M, Glintborg D \& Andersen M. Risk of impaired glucose tolerance in normal weight hirsute women during four years observation. Acta Obstetricia et Gynecologica Scandinavica 20108 1091-1095. (doi:10.3109/00016341003801680)

27 American Diabetes Association. Diagnosis and classification of diabetes mellitus. Diabetes Care 201134 S62-S69. (doi:10.2337/ dc11-S062)

28 Velling ML, Mumm H, Andersen M \& Glintborg D. Hemoglobin A1c as a tool for the diagnosis of type 2 diabetes in 208 premenopausal women with polycystic ovary syndrome. Fertility and Sterility 20115 1275-1280. (doi:10.1016/j.fertnstert.2011.08.035)

29 Selvin E, Steffes MW, Zhu H, Matsushita K, Wagenknecht L, Pankow J, Coresh J \& Brancati FL. Glycated hemoglobin, diabetes, and cardiovascular risk in nondiabetic adults. New England Journal of Medicine 20109 800-811. (doi:10.1056/NEJMoa0908359)
30 Khaw KT, Wareham N, Bingham S, Luben R, Welch A \& Day N. Association of hemoglobin A1c with cardiovascular disease and mortality in adults: the European prospective investigation into cancer in Norfolk. Annals of Internal Medicine 20046 413-420. (doi:10.7326/0003-4819-141-6-200409210-00006)

31 Levitan EB, Liu S, Stampfer MJ, Cook NR, Rexrode KM, Ridker PM, Buring JE \& Manson JE. HbA1c measured in stored erythrocytes and mortality rate among middle-aged and older women. Diabetologia 20082 267-275. (doi:10.1007/s00125-007-0882-y)

32 Wild RA, Carmina E, amanti-Kandarakis E, Dokras A, Escobar-Morreale HF, Futterweit W, Lobo R, Norman RJ, Talbott E \& Dumesic DA. Assessment of cardiovascular risk and prevention of cardiovascular disease in women with the polycystic ovary syndrome: a position statement by the androgen excess and polycystic ovary syndrome (AE-PCOS) society. Journal of Clinical Endocrinology and Metabolism 20105 2038-2049. (doi:10.1210/jc.2009-2724)

33 Macut D, Bjekic-Macut J \& Savic-Radojevic A. Dyslipidemia and oxidative stress in PCOS. Frontiers of Hormone Research $2013 \mathbf{4 0}$ 51-63.

34 Diamanti-Kandarakis E, Papavassiliou AG, Kandarakis SA \& Chrousos GP. Pathophysiology and types of dyslipidemia in PCOS. Trends in Endocrinology and Metabolism 20077 280-285. (doi:10.1016/j.tem.2007.07.004)

35 Glintborg D, Hojlund K, Andersen M, Henriksen JE, Beck-Nielsen H \& Handberg A. Soluble CD36 and risk markers of insulin resistance and atherosclerosis are elevated in polycystic ovary syndrome and significantly reduced during pioglitazone treatment. Diabetes Care 20082 328-334. (doi:10.2337/dc07-1424)

36 Glintborg D, Mumm H, Hougaard D, Ravn P \& Andersen M. Ethnic differences in Rotterdam criteria and metabolic risk factors in a multiethnic group of women with PCOS studied in Denmark. Clinical Endocrinology 20106 732-738. (doi:10.1111/j.13652265.2010.03873.x)

37 Glintborg D, Mumm H, Ravn P \& Andersen M. Age associated differences in prevalence of individual rotterdam criteria and metabolic risk factors during reproductive age in 446 caucasian women with polycystic ovary syndrome. Hormone and Metabolic Research 20129 694-698. (doi:10.1055/s-0032-1304608)

38 Banaszewska B, Pawelczyk L, Spaczynski RZ, Dziura J \& Duleba AJ. Effects of simvastatin and oral contraceptive agent on polycystic ovary syndrome: prospective, randomized, crossover trial. Journal of Clinical Endocrinology and Metabolism 20072 456-461. (doi:10.1210/ jc.2006-1988)

39 Puurunen J, Piltonen T, Puukka K, Ruokonen A, Savolainen MJ, Bloigu R, Morin-Papunen L \& Tapanainen JS. Statin therapy worsens insulin sensitivity in women with polycystic ovary syndrome (PCOS): a prospective, randomized, double-blind, placebo-controlled study. Journal of Clinical Endocrinology and Metabolism 201312 4798-4807. (doi:10.1210/jc.2013-2674)

40 Elting MW, Korsen TJ, Bezemer PD \& Schoemaker J. Prevalence of diabetes mellitus, hypertension and cardiac complaints in a follow-up study of a Dutch PCOS population. Human Reproduction 20013 556-560. (doi:10.1093/humrep/16.3.556)

41 Wild S, Pierpoint T, McKeigue P \& Jacobs H. Cardiovascular disease in women with polycystic ovary syndrome at long-term follow-up: a retrospective cohort study. Clinical Endocrinology 20005 595-600. (doi:10.1046/j.1365-2265.2000.01000.x)

42 Moran LJ, Noakes M, Clifton PM, Wittert G, Tomlinson L, Galletly C, Luscombe N, Tomlinson L \& Norman RJ. Ghrelin and measures of satiety are altered in polycystic ovary syndrome but not differentially affected by diet composition. Journal of Clinical Endocrinology \& Metabolism 200489 3337-3344. (doi:10.1210/ jc.2003-031583)

43 Mumm H, Altinok ML, Henriksen JE, Ravn P, Glintborg D \& Andersen M. Prevalence and possible mechanisms of reactive 
hypoglycemia in polycystic ovary syndrome. Human Reproduction 201631 1105-1112. (doi:10.1093/humrep/dew046)

44 Wild RA, Painter PC, Coulson PB, Carruth KB \& Ranney GB. Lipoprotein lipid concentrations and cardiovascular risk in women with polycystic ovary syndrome. Journal of Clinical Endocrinology and Metabolism 19855 946-951. (doi:10.1210/jcem-61-5-946)

45 Barr S, Hart K, Reeves S \& Jeanes Y. Dietary intake, body composition and physical activity levels in women with polycystic ovary syndrome compared with healthy controls. Journal of Human Nutrition and Dietetics 20084 377. (doi:10.1111/j.1365277X.2008.00881_6.X)

46 Morgan J, Scholtz S, Lacey H \& Conway G. The prevalence of eating disorders in women with facial hirsutism: an epidemiological cohort study. International Journal of Eating Disorders 20085 427-431. (doi:10.1002/eat.20527)

47 Naessen S, Carlstrom K, Garoff L, Glant R \& Hirschberg AL. Polycystic ovary syndrome in bulimic women - an evaluation based on the new diagnostic criteria. Gynecological Endocrinology 20067 388-394. (doi:10.1080/09513590600847421)

48 Glintborg D, Mumm H, Hougaard DM, Ravn P \& Andersen M. Smoking is associated with increased adrenal responsiveness, decreased prolactin levels and a more adverse lipid profile in 650 white patients with polycystic ovary syndrome. Gynecological Endocrinology 20123 170-174. (doi:10.3109/09513590.2011. 589926)

49 Legro RS, Chen G, Kunselman AR, Schlaff WD, Diamond MP, Coutifaris C, Carson SA, Steinkampf MP, Carr BR, McGovern PG et al. Smoking in infertile women with polycystic ovary syndrome: baseline validation of self-report and effects on phenotype. Human Reproduction 201412 2680-2686. (doi:10.1093/humrep/deu239)

50 Bajuk SK, Jensterle SM \& Pfeifer M. Cardiovascular risk and subclinical cardiovascular disease in polycystic ovary syndrome. Frontiers of Hormone Research $2013 \mathbf{4 0}$ 64-82.

51 Apridonidze T, Essah PA, Iuorno MJ \& Nestler JE. Prevalence and characteristics of the metabolic syndrome in women with polycystic ovary syndrome. Journal of Clinical Endocrinology and Metabolism 200590 1929-1935. (doi:10.1210/jc.2004-1045)

52 Christian RC, Dumesic DA, Behrenbeck T, Oberg AL, Sheedy PF \& Fitzpatrick LA. Prevalence and predictors of coronary artery calcification in women with polycystic ovary syndrome. Journal of Clinical Endocrinology and Metabolism 20036 2562-2568. (doi:10.1210/jc.2003-030334)

53 Taponen S, Martikainen H, Jarvelin MR, Sovio U, Laitinen J, Pouta A, Hartikainen AL, McCarthy MI, Franks S, Paldanius M et al. Metabolic cardiovascular disease risk factors in women with self-reported symptoms of oligomenorrhea and/or hirsutism: Northern Finland Birth Cohort 1966 Study. Obstetrical and Gynecological Survey 20051 37-39. (doi:10.1097/01.ogx.0000143796.59741.2d)

54 Dokras A. Cardiovascular disease risk in women with PCOS. Steroids 20138 773-776. (doi:10.1016/j.steroids.2013.04.009)

55 de Groot PC, Dekkers OM, Romijn JA, Dieben SW \& Helmerhorst FM. PCOS, coronary heart disease, stroke and the influence of obesity: a systematic review and meta-analysis. Human Reproduction Update 20114 495-500. (doi:10.1093/humupd/dmr001)

56 Moran L \& Teede H. Metabolic features of the reproductive phenotypes of polycystic ovary syndrome. Human Reproduction Update 20094 477-488. (doi:10.1093/humupd/dmp008)

57 Moran LJ, Norman RJ \& Teede HJ. Metabolic risk in PCOS: phenotype and adiposity impact. Trends in Endocrinology and Metabolism 20153 136-143. (doi:10.1016/j.tem.2014.12.003)

58 Azziz R, Carmina E, Dewailly D, Amanti-Kandarakis E, Escobar-Morreale HF, Futterweit W, Janssen OE, Legro RS, Norman RJ, Taylor AE et al. The Androgen Excess and PCOS Society criteria for the polycystic ovary syndrome: the complete task force report. Fertility and Sterility 20092 456-488. (doi:10.1016/j.fertnstert.2008.06.035)
59 Moran LJ, Brinkworth GD \& Norman RJ. Dietary therapy in polycystic ovary syndrome. Seminars in Reproductive Medicine 20081 85-92. (doi:10.1055/s-2007-992928)

60 Daryani A, Berglund L, Andersson A, Kocturk T, Becker W \& Vessby B. Risk factors for coronary heart disease among immigrant women from Iran and Turkey, compared to women of Swedish ethnicity. Ethnicity and Disease 20052 213-220.

61 Costello M, Shrestha B, Eden J, Sjoblom P \& Johnson N. Insulin-sensitising drugs versus the combined oral contraceptive pill for hirsutism, acne and risk of diabetes, cardiovascular disease, and endometrial cancer in polycystic ovary syndrome. Cochrane Database of Systematic Reviews 20071 CD005552. (doi:10.1002/14651858. cd005552.pub2)

62 Halperin IJ, Kumar SS, Stroup DF \& Laredo SE. The association between the combined oral contraceptive pill and insulin resistance, dysglycemia and dyslipidemia in women with polycystic ovary syndrome: a systematic review and meta-analysis of observational studies. Human Reproduction 20111 191-201. (doi:10.1093/humrep/ deq301)

63 Kriplani A, Periyasamy AJ, Agarwal N, Kulshrestha V, Kumar A \& Ammini AC. Effect of oral contraceptive containing ethinyl estradiol combined with drospirenone vs. desogestrel on clinical and biochemical parameters in patients with polycystic ovary syndrome. Contraception 20102 139-146. (doi:10.1016/ j.contraception.2010.02.009)

64 Glintborg D, Altinok ML, Mumm H, Hermann AP, Ravn P \& Andersen M. Body composition is improved during 12 months treatment with metformin alone or combined with oral contraceptives compared to treatment with oral contraceptives in polycystic ovary syndrome. Journal of Clinical Endocrinology and Metabolism 201499 2584-2591. (doi:10.1210/jc.2014-1135)

65 Domecq JP, Prutsky G, Mullan RJ, Sundaresh V, Wang AT, Erwin PJ, Welt C, Ehrmann D, Montori VM \& Murad MH. Adverse effects of the common treatments for polycystic ovary syndrome: a systematic review and meta-analysis. Journal of Clinical Endocrinology and Metabolism 201312 4646-4654. (doi:10.1210/jc.2013-2374)

66 Bates GW \& Legro RS. Longterm management of Polycystic Ovarian Syndrome (PCOS). Molecular and Cellular Endocrinology 2013 1-2 91-97. (doi:10.1016/j.mce.2012.10.029)

67 Nader S \& Diamanti-Kandarakis E. Polycystic ovary syndrome, oral contraceptives and metabolic issues: new perspectives and a unifying hypothesis. Human Reproduction 20072 317-322. (doi:10.1093/ humrep/del407)

68 Bird ST, Hartzema AG, Brophy JM, Etminan M \& Delaney JA. Risk of venous thromboembolism in women with polycystic ovary syndrome: a population-based matched cohort analysis. Canadian Medical Association Journal 20132 E115-E120. (doi:10.1503/ cmaj.120677)

69 Gronich N, Lavi I \& Rennert G. Higher risk of venous thrombosis associated with drospirenone-containing oral contraceptives: a population-based cohort study. Canadian Medical Association Journal 201118 E1319-E1325. (doi:10.1503/cmaj.110463)

70 Ravn P, Haugen AG \& Glintborg D. Overweight in polycystic ovary syndrome. An update on evidence based advice on diet, exercise and metformin use for weight loss. Minerva Endocrinologica 20131 59-76.

71 Cosar E, Koken G, Sahin FK, Akgun L, Ucok K, Genc A \& Yilmazer M. Resting metabolic rate and exercise capacity in women with polycystic ovary syndrome. International Journal of Gynecology and Obstetrics 20081 31-34. (doi:10.1016/j.ijgo.2007.10.011)

72 Pasquali R, Gambineri A, Biscotti D, Vicennati V, Gagliardi L, Colitta D, Fiorini S, Cognigni GE, Filicori M \& Morselli-Labate AM. Effect of long-term treatment with metformin added to hypocaloric diet on body composition, fat distribution, and androgen and insulin levels in abdominally obese women with and without the polycystic ovary syndrome. Journal of Clinical Endocrinology and Metabolism 20008 2767-2774. (doi:10.1210/jcem.85.8.6738) 
73 Moran LJ, Noakes M, Clifton PM, Wittert GA, Le Roux CW, Ghatei MA, Bloom SR \& Norman RJ. Postprandial ghrelin, cholecystokinin, peptide YY, and appetite before and after weight loss in overweight women with and without polycystic ovary syndrome. American Journal of Clinical Nutrition 20076 1603-1610.

74 Palomba S, Falbo A, Zullo F \& Orio F Jr. Evidence-based and potential benefits of metformin in the polycystic ovary syndrome: a comprehensive review. Endocrine Reviews 2009 1 1-50. (doi:10.1210/ er.2008-0030)

75 Kanat M, DeFronzo RA \& Abdul-Ghani MA. Treatment of prediabetes. World Journal of Diabetes 201512 1207-1222.

76 Gagnon J, Sheppard E \& Anini Y. Metformin directly inhibits ghrelin secretion through AMP-activated protein kinase in rat primary gastric cells. Diabetes, Obesity and Metabolism 2013 276-279. (doi:10.1111/dom.12021)

77 Gregoriou O, Kouskouni E, Bakas P, Konidaris S, Papadias K, Kalovidouris A \& Creatsas G. Bone mineral density in women with idiopathic hirsutism. Gynecological Endocrinology 20005 364-368. (doi:10.3109/09513590009167704)

78 Reid IR, Plank LD \& Evans MC. Fat mass is an important determinant of whole body bone density in premenopausal women but not in men. Journal of Clinical Endocrinology and Metabolism 1992 3 779-782. (doi:10.1210/jcem.75.3.1517366)

79 Christensen JO \& Svendsen OL. Bone mineral in pre- and postmenopausal women with insulin-dependent and non-insulindependent diabetes mellitus. Osteoporosis International 19994 307-311. (doi:10.1007/s001980050232)

80 Abrahamsen B, Rohold A, Henriksen JE \& Beck-Nielsen H. Correlations between insulin sensitivity and bone mineral density in non-diabetic men. Diabetic Medicine 20002 124-129. (doi:10.1046/ j.1464-5491.2000.00234.x)

81 Glintborg D, Hermann A \& Andersen M. Bone mineral density and vitamin D in PCOS and hirsutism. Expert Review of Endocrinology and Metabolism 20135 449-459. (doi:10.1586/17446651.2013.827384)

82 Rubin KH, Glintborg D, Nybo M, Andersen M \& Abrahamsen B. Fracture risk is decreased in women with polycystic ovary syndrome: A register- and population-based cohort study. Journal of Bone and Mineral Research 201631 709-717. (doi:10.1002/jbmr.2737)

83 Glintborg D, Andersen M, Hagen C \& Hermann AP. Higher bone mineral density in Caucasian, hirsute patients of reproductive age. Positive correlation of testosterone levels with bone mineral density in hirsutism. Clinical Endocrinology 20056 683-691. (doi:10.1111/ j.1365-2265.2005.02280.x)

84 Li HW, Brereton RE, Anderson RA, Wallace AM \& Ho CK. Vitamin D deficiency is common and associated with metabolic risk factors in patients with polycystic ovary syndrome. Metabolism $2011 \mathbf{1 0}$ 1475-1481. (doi:10.1016/j.metabol.2011.03.002)

85 Thomson RL, Spedding S, Brinkworth GD, Noakes M \& Buckley JD. Seasonal effects on vitamin D status influence outcomes of lifestyle intervention in overweight and obese women with polycystic ovary syndrome. Fertility and Sterility 20136 1779-1785. (doi:10.1016/ j.fertnstert.2012.12.042)

86 Schmidt J, Dahlgren E, Brannstrom M \& Landin-Wilhelmsen K. Body composition, bone mineral density and fractures in late postmenopausal women with polycystic ovary syndrome - a long-term follow-up study. Clinical Endocrinology 20122 207-214. (doi:10.1111/j.1365-2265.2012.04378.x)

87 Lopez LM, Grimes DA, Schulz KF \& Curtis KM. Steroidal contraceptives: effect on bone fractures in women. Cochrane Database of Systematic Reviews 20117 CD006033. (doi:10.1002/14651858.cd006033.pub4)

88 Tremollieres F. Impact of oral contraceptive on bone metabolism. Best Practice and Research Clinical Endocrinology and Metabolism 2013 1 47-53. (doi:10.1016/j.beem.2012.09.002)

89 Castelo-Branco C, Martinez de Osaba MJ, Pons F \& Fortuny A. Gonadotropin-releasing hormone analog plus an oral contraceptive containing desogestrel in women with severe hirsutism: effects on hair, bone, and hormone profile after 1-year use. Metabolism 19974 437-440. (doi:10.1016/S0026-0495(97)90062-7)

90 Gregoriou O, Bakas P, Konidaris S, Papadias K, Mathiopoulos D $\&$ Creatsas $\mathrm{G}$. The effect of combined oral contraception with or without spironolactone on bone mineral density of hyperandrogenic women. Gynecological Endocrinology 20005 369-373. (doi:10.3109/09513590009167705)

91 Rejnmark L. Bone effects of glitazones and other anti-diabetic drugs. Current Drug Safety 20083 194-198. (doi:10.2174/157488608785699 478)

92 Bechtold S, Dalla PR, Putzker S, Roeb J, Buckel M, Weissenbacher C \& Schmidt H. Effect of antiandrogen treatment on bone density and bone geometry in adolescents with polycystic ovary syndrome. Journal of Pediatric and Adolescent Gynecology 20123 175-180. (doi:10.1016/j.jpag.2011.11.010)

93 Miyazaki Y, Mahankali A, Matsuda M, Mahankali S, Hardies J, Cusi K, Mandarino LJ \& DeFronzo RA. Effect of pioglitazone on abdominal fat distribution and insulin sensitivity in type 2 diabetic patients. Journal of Clinical Endocrinology and Metabolism 20026 2784-2791. (doi:10.1210/jcem.87.6.8567)

94 Glintborg D \& Andersen M. Thiazolinedione treatment in polycystic ovary syndrome. Gynecological Endocrinology 201026 791-803. (doi:10.3109/09513590.2010.491572)

95 Ali AA, Weinstein RS, Stewart SA, Parfitt AM, Manolagas SC \& Jilka RL. Rosiglitazone causes bone loss in mice by suppressing osteoblast differentiation and bone formation. Endocrinology 20053 1226-1235. (doi:10.1210/en.2004-0735)

96 Glintborg D, Andersen M, Hagen C, Heickendorff L \& Hermann AP. Association of pioglitazone treatment with decreased bone mineral density in obese premenopausal patients with polycystic ovary syndrome: a randomized, placebo-controlled trial. Journal of Clinical Endocrinology and Metabolism 20085 1696-1701. (doi:10.1210/ jc.2007-2249)

97 Kahn SE, Haffner SM, Heise MA, Herman WH, Holman RR, Jones NP, Kravitz BG, Lachin JM, O'Neill MC, Zinman B et al. Glycemic durability of rosiglitazone, metformin, or glyburide monotherapy. New England Journal of Medicine 200623 2427-2443. (doi:10.1056/ NEJMoa066224)

98 Grey A, Bolland M, Gamble G, Wattie D, Horne A, Davidson J \& Reid IR. The peroxisome proliferator-activated receptor-gamma agonist rosiglitazone decreases bone formation and bone mineral density in healthy postmenopausal women: a randomized, controlled trial. Journal of Clinical Endocrinology and Metabolism 2007 4 1305-1310. (doi:10.1210/jc.2006-2646)

99 Al-Saab R \& Haddad S. Detection of thyroid autoimmunity markers in euthyroid women with polycystic ovary syndrome: a case-control study from syria. International Journal of Endocrinology and Metabolism 20143 e17954. (doi:10.5812/ijem.17954)

100 Novais JD, Benetti-Pinto CL, Garmes HM, Menezes JR \& Juliato CR. Polycystic ovary syndrome and chronic autoimmune thyroiditis. Gynecological Endocrinology 201531 48-51. (doi:10.3109/09513590. 2014.958990)

101 Macsali F, Svanes C, Bjorge L, Omenaas ER \& Gomez RF. Respiratory health in women: from menarche to menopause. Expert Review of Respiratory Medicine 20122 187-200. (doi:10.1586/ers.12.15)

102 Codner E \& Escobar-Morreale HF. Clinical review: hyperandrogenism and polycystic ovary syndrome in women with type 1 diabetes mellitus. Journal of Clinical Endocrinology and Metabolism 20074 1209-1216. (doi:10.1210/jc.2006-2641)

103 Amato MC, Guarnotta V, Ciresi A, Modica R, Panto F \& Giordano C. No phenotypic differences for polycystic ovary syndrome (PCOS) between women with and without type 1 diabetes mellitus. Journal of Clinical Endocrinology and Metabolism 201412 203-211. (doi:10.1210/jc.2013-2669) 
104 Aune D \& Vatten LJ. Diabetes mellitus and the risk of gallbladder disease: a systematic review and meta-analysis of prospective studies. Journal of Diabetes and Its Complications 20162 368-373. (doi:10.1016/j.jdiacomp.2015.11.012)

105 Isik S, Ozcan HN, Ozuguz U, Berker D, Tutuncu Y, Akbaba G \& Guler S. Impaired gallbladder motility and the effect of metformin therapy in patients with polycystic ovary syndrome. Clinical Endocrinology 20123 373-378. (doi:10.1111/j.13652265.2011.04210.x)

106 Jick S \& Pennap D. Drospirenone- and levonorgestrel-containing oral contraceptives and the risk of gallbladder disease. Contraception 20123 220-223. (doi:10.1016/j.contraception.2012.01.006)

107 Ramezani-Binabaj M, Motalebi M, Karimi-Sari H, RezaeeZavareh MS \& Alavian SM. Are women with polycystic ovarian syndrome at a high risk of non-alcoholic Fatty liver disease; a meta-analysis. Hepatitis Monthly 201411 e23235. (doi:10.5812/ hepatmon.23235)

108 Yoneda M, Thomas E, Sumida Y, Eguchi Y \& Schiff ER. The influence of menopause on the development of hepatic fibrosis in nonobese women with nonalcoholic fatty liver disease. Hepatology 20145 1792. (doi:10.1002/hep.27097)

109 Cinar N, Kizilarslanoglu MC, Harmanci A, Aksoy DY, Bozdag G, Demir B \& Yildiz BO. Depression, anxiety and cardiometabolic risk in polycystic ovary syndrome. Human Reproduction 201112 3339-3345. (doi:10.1093/humrep/der338)

110 Jones GL, Hall JM, Balen AH \& Ledger WL. Health-related quality of life measurement in women with polycystic ovary syndrome: a systematic review. Human Reproduction Update 2008 1 15-25. (doi:10.1093/humupd/dmm030)

111 Hahn S, Janssen OE, Tan S, Pleger K, Mann K, Schedlowski M, Kimmig R, Benson S, Balamitsa E \& Elsenbruch S. Clinical and psychological correlates of quality-of-life in polycystic ovary syndrome. European Journal of Endocrinology 20056 853-860. (doi:10.1530/eje.1.02024)

112 Dokras A, Clifton S, Futterweit W \& Wild R. Increased risk for abnormal depression scores in women with polycystic ovary syndrome: a systematic review and meta-analysis. Obstetrics and Gynecology 20111 145-152. (doi:10.1097/AOG.0b013e318202b0a4)

113 Crave JC, Fimbel S, Lejeune H, Cugnardey N, Dechaud H \& Pugeat M. Effects of diet and metformin administration on sex hormone-binding globulin, androgens, and insulin in hirsute and obese women. Journal of Clinical Endocrinology and Metabolism $1995 \mathbf{7}$ 2057-2062. (doi:10.1210/jc.80.7.2057)

114 Zhuang J, Wang X, Xu L, Wu T \& Kang D. Antidepressants for polycystic ovary syndrome. Cochrane Database of Systematic Reviews 2013 CD008575. (doi:10.1002/14651858.CD008575.pub2)

115 Hung JH, Hu LY, Tsai SJ, Yang AC, Huang MW, Chen PM, Wang SL, Lu T \& Shen CC. Risk of psychiatric disorders following polycystic ovary syndrome: a nationwide population-based cohort study. PLoS ONE 20145 e97041. (doi:10.1371/journal.pone.0097041)

116 Cinar N, Harmanci A, Demir B \& Yildiz BO. Effect of an oral contraceptive on emotional distress, anxiety and depression of women with polycystic ovary syndrome: a prospective study. Human Reproduction 20126 1840-1845. (doi:10.1093/humrep/ des113)

117 Hahn S, Benson S, Elsenbruch S, Pleger K, Tan S, Mann K, Schedlowski M, van Halteren WB, Kimmig R \& Janssen OE. Metformin treatment of polycystic ovary syndrome improves health-related quality-of-life, emotional distress and sexuality.
Human Reproduction 20067 1925-1934. (doi:10.1093/humrep/ del069)

118 Glaser R, Dimitrakakis C, Trimble N \& Martin V. Testosterone pellet implants and migraine headaches: a pilot study. Maturitas 20124 385-388. (doi:10.1016/j.maturitas.2012.01.006)

119 Check JH, Cohen R. Dihydrotestosterone may contribute to the development of migraine headaches. Clinical and Experimental Obstetrics and Gynecology 20132 217-218.

120 Holm NS, Glintborg D, Andersen MS, Schledermann D \& Ravn P. The prevalence of endometrial hyperplasia and endometrial cancer in women with polycystic ovary syndrome or hyperandrogenism. Acta Obstetricia et Gynecologica Scandinavica 201210 1173-1176. (doi:10.1111/j.1600-0412.2012.01458.x)

121 Hardiman P, Pillay OC \& Atiomo W. Polycystic ovary syndrome and endometrial carcinoma. Lancet 20039371 1810-1812. (doi:10.1016/ S0140-6736(03)13409-5)

122 Gottschau M, Kjaer SK, Jensen A, Munk C \& Mellemkjaer L. Risk of cancer among women with polycystic ovary syndrome: a Danish cohort study. Gynecologic Oncology 20151 99-103. (doi:10.1016/ j.ygyno.2014.11.012)

123 Barry JA, Azizia MM \& Hardiman PJ. Risk of endometrial, ovarian and breast cancer in women with polycystic ovary syndrome: a systematic review and meta-analysis. Human Reproduction Update 20145 748-758. (doi:10.1093/humupd/dmu012)

124 Cattrall FR, Healy DL. Long-term metabolic, cardiovascular and neoplastic risks with polycystic ovary syndrome. Best Practice and Research Clinical Obstetrics and Gynaecology 20045 803-812. (doi:10.1016/j.bpobgyn.2004.05.005)

125 Vigneri R, Goldfine ID \& Frittitta L. Insulin, insulin receptors, and cancer. Journal of Endocrinological Investigation 2016 In press. (doi:10.1007/s40618-016-0508-7)

126 Charlson ME, Pompei P, Ales KL \& MacKenzie CR. A new method of classifying prognostic comorbidity in longitudinal studies: development and validation. Journal of Chronic Diseases 19875 373-383. (doi:10.1016/0021-9681(87)90171-8)

127 Quan H, Sundararajan V, Halfon P, Fong A, Burnand B, Luthi JC, Saunders LD, Beck CA, Feasby TE \& Ghali WA. Coding algorithms for defining comorbidities in ICD-9-CM and ICD-10 administrative data. Medical Care 200511 1130-1139. (doi:10.1097/01. mlr.0000182534.19832.83)

128 Morgan CL, Jenkins-Jones S, Currie CJ \& Rees DA. Evaluation of adverse outcome in young women with polycystic ovary syndrome versus matched, reference controls: a retrospective, observational study. Journal of Clinical Endocrinology and Metabolism 20129 3251-3260. (doi:10.1210/jc.2012-1690)

129 Mani H, Levy MJ, Davies MJ, Morris DH, Gray LJ, Bankart J, Blackledge H, Khunti K \& Howlett TA. Diabetes and cardiovascular events in women with polycystic ovary syndrome: a 20-year retrospective cohort study. Clinical Endocrinology 20136 926-934. (doi:10.1111/cen.12068)

130 Alvarez-Blasco F, Luque-Ramirez M \& Escobar-Morreale HF. Diet composition and physical activity in overweight and obese premenopausal women with or without polycystic ovary syndrome. Gynecological Endocrinology 201112 978-981. (doi:10.3109/09513590. 2011.579658)

131 Eleftheriadou M, Michala L, Stefanidis K, Iliadis I, Lykeridou A \& Antsaklis A. Exercise and sedentary habits among adolescents with PCOS. Journal of Pediatric and Adolescent Gynecology 20123 172-174. (doi:10.1016/j.jpag.2011.11.009)

Received 27 April 2016

Revised version received 17 August 2016

Accepted 5 September 2016 